Bes, R.E., Curfs, E.C., Groenewegen, P.P., Jong, J.D. de. Health plan choice in the Netherlandsh restrictive health plans preferred by young and healthy individuals. Health Economics, Policy and Law: 2017, 12(3), 345-362

\begin{tabular}{|l|l|}
$\begin{array}{l}\text { Postprint } \\
\text { Version }\end{array}$ & 1.0 \\
\hline Journal website & $\underline{\text { http://dx.doi.org/10.1017/S1744133116000517 }}$ \\
\hline Pubmed link & $\underline{\text { https://www.ncbi.nlm.nih.gov/pubmed/28290918 }}$ \\
\hline DOI & $10.1017 /$ S1744133116000517
\end{tabular}

This is a NIVEL certified Post Print, more info at http://www.nivel.eu

\title{
Health plan choice in the Netherlands: restrictive health plans preferred by young and healthy individuals
}

\author{
Romy E. Bes ${ }^{(\mathrm{A} 1)(\mathrm{A} 2)}$, EMILE C. CURFS ${ }^{(\mathrm{A} 2)}$, Peter P. GROENEWEGEN ${ }^{(\mathrm{A} 1)}$ AND JUdith D. DE \\ $\mathrm{JONG}^{(\mathrm{A} 1)}$ \\ (a1) 1 Netherlands Institute for Health Services Research (NIVEL), Otterstraat 118-124, 3513 \\ $\mathrm{CR}$, Utrecht, The Netherlands \\ (a2) 2 Open University, Valkenburgerweg 177, 6419 AT, Heerlen, The Netherlands
}

\begin{abstract}
In a health care system based on managed competition, health insurers negotiate on quality and price with care providers and are allowed to offer restrictive health plans. It is crucial that enrolees who need care choose restrictive health plans, as otherwise health insurers cannot channel patients to contracted providers and they will lose their bargaining power in negotiations with providers. We aim to explain enrolees' choice of a restrictive health plan in exchange for a lower premium. In 2014 an online survey with an experimental design was conducted on members of an access panel (response $78 \%$; $n=3,417$ ). Results showed $37.4 \%$ of respondents willing to choose a restrictive health plan in exchange for a lower premium. This fell to $22 \%$ when the restrictive health plan also included a longer travelling time. Enrolees who choose a restrictive health plan are younger and healthier, or on lower incomes, than those preferring a non-restrictive one. This means that enrolees who use care will be unlikely to choose a restrictive health plan and, therefore, health insurers will not be able to channel them to contracted care providers. This undermines the goals of the health care system based on managed competition.
\end{abstract}

\section{INTRODUCTION}

Several countries have implemented health care systems based on managed competition, for instance Germany, Switzerland and the Netherlands (LaskeAldershof et al., 2004; Van de Ven et al., 2013). In a health care system based on managed competition, the idea is that third party payers prudently purchase care based on price and quality on behalf of their clients, the patients (Enthoven, 1993). These third party payers are usually health insurers, but they can also be employers or government bodies. Enrolees are allowed to switch health plans and, therefore, health insurers are supposed to compete with each other for enrolees by trying to offer the best health plans in terms of quality and price. Health insurers are allowed 
Bes, R.E., Curfs, E.C., Groenewegen, P.P., Jong, J.D. de. Health plan choice in the Netherlandsh restrictive health plans preferred by young and healthy individuals. Health Economics, Policy and Law: 2017, 12(3), 345-362

to contract care providers selectively, which means that they do not have to contract all care providers. In order to keep their revenue, care providers will compete with each other to be contracted by health insurers. This competition between care providers should lead to increased quality of care, while costs are contained. The idea is that health insurers will have a better bargaining position in negotiations with care providers if they can successfully channel their enrolees to contracted care providers, as this will imply a loss of business for non-contracted care providers (Sorensen, 2003; Boonen and Schut, 2011). Selective contracting, which means that the choice of care providers is more restrictive, can be conducted in preferred provider networks and in exclusive networks. In a preferred provider network, costs are only partially reimbursed if enrolees go to a non-contracted care provider. In an exclusive network, care providers who are not contracted are not reimbursed at all. The idea of a system of managed competition is that health insurers select care providers based on price and quality. Care providers are supposed to compete with each other to be included in a health plan's network, as that will increase their number of patients and thus their revenues. This should lead to better quality of care and a reduction in health care costs.

Channelling enrolees to contracted care providers is important for the health care system to reach its goals of improving the quality of care and reducing costs (Sorensen, 2003; Wu, 2009). It was shown that financial incentives in restrictive health plans are effective in channelling patients to contracted care providers (Boonen et al., 2008, 2009; Bes et al., 2015). However, restrictive health plans are not favoured by enrolees (Bes et al., 2013). Enrolees are sensitive to negative aspects of restrictions in their choice of care provider. For example, the fact that their health insurer is involved in the choice of care provider and that enrolees may have to travel further to the nearest care provider. A positive aspect, however, is that restrictive health plans are usually cheaper for enrolees compared with health plans with a free choice of provider.

However, research from the United States shows that enrolees who have a restrictive health plan are less satisfied with their health plan and their care providers (Davis et al., 1995; Schmittdiel et al., 1997; Tai-Seale and Pescosolido, 2003; Chu-Weininger and Balkrishnan, 2006). This was the case even though it was shown that the quality of care providers in restrictive health plans is equal or even better than care in nonrestrictive health plans (Chernew et al., 1998; Kemper et al., 2002). However, when enrolees have chosen a restrictive health plan themselves, rather then it being appointed to them (e.g. by their employer which is common in the United States), enrolees are more positive about their health plan and their care providers. Therefore, it seems to be important that enrolees have a choice between different types of health plans (Davis et al., 1995; Dutch Health Care Authority, 2007). An important question is, who would choose a restrictive health plan and, thus, accept restrictions in provider choice, and maybe a longer distance to travel as well, for a lower premium? If the health care system is to reach its intended goals of improving quality and reducing health care costs, it is important that not only young and healthy enrolees, but also enrolees who actually use care, choose a restrictive health plan. Because, when only healthy enrolees, who rarely use care, choose a restrictive health plan, care providers will not notice a loss of business when they are not contracted, as 
Bes, R.E., Curfs, E.C., Groenewegen, P.P., Jong, J.D. de. Health plan choice in the Netherlandsh restrictive health plans preferred by young and healthy individuals. Health Economics, Policy and Law: 2017, 12(3), 345-362

enrolees who use care do not have a restrictive health plan and keep visiting the same care providers. Thus, there will be no incentive for competition between care providers and, according to Enthoven's theory, no incentive to improve health care quality while costs are controlled. Restrictive health plans could still be cheaper compared with non-restrictive health plans, because of favourable selection bias, but this would mean that the health care system does not work as intended. Some research on who chooses a restrictive health plan has been carried out in the United States, but not yet in the Netherlands, and there are significant differences in health care systems between the two countries, for instance in the Netherlands people are obliged to have health insurance and historically, they are used to having free choice of care provider (Enthoven, 2008). Therefore, this study will focus on the Dutch situation. It will also be relevant for other countries implementing a system of managed competition, especially where, like in the Netherlands, a transfer from a supply-oriented, social health insurance system, to a managed competition system with a free choice of health plan is intended. The research question that will be answered in this paper is: What are the demographic characteristics of people who are willing to choose a restrictive health plan? Furthermore, we aim to explain why different groups of enrolees would choose a restrictive health plan or not.

\subsection{Context}

Research in the United States has been conducted on who chooses Health Maintenance Organisation (HMO) plans, i.e. health plans which restrict provider choice. This was mainly in order to find out whether HMO plans are experiencing favourable selection bias, where younger and healthier enrolees enrol more often in these type of health plans (e.g. Hellinger, 1995; Hellinger and Wong, 2000; Mello et al., 2003). Literature reviews by Hellinger show that healthier enrolees are more likely to enrol in an HMO plan. People who actually need to use care are less willing to choose a restrictive health plan, probably because they do not want to change care providers as they already have an established relationship with their current care provider (Hellinger, 1995; Hellinger and Wong, 2000). In Switzerland too, HMO plans experience favourable selection bias as enrolees of HMO plans are on average seven years younger than enrolees of conventional health plans (Lehman and Zweifel, 2004).

Ever since health plans in the United States increased freedom of choice in response to a collective resentment against managed care, out-of-pocket payments have grown rapidly in order to keep health care affordable (Tu, 2005). Research, therefore, now shows an increasing willingness of enrolees to give up freedom of provider choice in exchange for lower out-of-pocket payments (from 55 to 59\%) (Tu, 2005). It was found that adults on a low income are more willing to accept restrictions on their freedom of choice in exchange for lower costs compared with adults earning a higher income. But the difference is not large. In addition, it was found that adults suffering from a chronic illness are less willing to accept restrictions on their freedom of choice in exchange for lower costs compared with adults enjoying better health. This is likely because they do not want to risk having to switch care providers. However, the difference in willingness to accept restrictions on their freedom of choice in exchange for lower costs, between the two groups is small. The effect is likely 
Bes, R.E., Curfs, E.C., Groenewegen, P.P., Jong, J.D. de. Health plan choice in the Netherlandsh restrictive health plans preferred by young and healthy individuals. Health Economics, Policy and Law: 2017, 12(3), 345-362

cancelled out by a higher price-sensitivity of patients with chronic health conditions compared with enrolees who hardly use care. Patients with chronic conditions are more price sensitive because, in the United States, enrolees have a high burden of out-of-pocket costs (Tu, 2005). Although the chronically ill in the Netherlands probably pay somewhat more compared with people in better health, the difference is not very large (Rijken et al., 2015). Therefore, it is likely that in the Netherlands people with chronic conditions will be less willing to accept a restrictive health plan in exchange for a lower premium.

Basic health plans are all the same, as the government determines the content in terms of care; but the freedom of provider choice and the premiums differ between different health insurers or health plans. For instance, midwifery care is included in the basic health plan, so all health insurers have to offer this type of care. However, health insurers are free to contract only a certain number of care providers that offer midwifery care. In general, more freedom of choice means a more expensive premium. If enrolees use providers with whom the insurers do not have a contract, then enrolees will have to pay part of the costs themselves.

Typical of the Dutch health care system is that before the introduction of managed competition in 2006, there was a social health insurance system in which people experienced freedom of provider choice. Therefore, health insurers are reluctant to implement selective contracting, because they expect that their enrolees will not accept it and change insurers (Boonen and Schut, 2011). Even so, restrictive health plans are currently being introduced and most health insurers offer restrictive health plans as well as non-restrictive ones. In 2015, around 7.5\% of enrolees in the Netherlands has a restrictive health plan (Dutch Health Care Authority, 2015).

Meanwhile, it has also been shown that many people in the Netherlands do not know what selective contracting is, and indeed, that it entails a restriction of provider choice (Bes et al., 2014). When it is explained to people what selective contracting is, it was found that Dutch enrolees are very negative about such restrictions (Bes et al., 2013). However, because it was found that a lot of people do not know what selective contracting is, it is not clear whether enrolees of restrictive health plans in the Netherlands consciously chose this restrictive health plan in exchange for a lower premium or whether they only looked at the premium and did not realise these health plans have a restricted care provider choice. Thus, it is unclear who would in fact choose a restrictive health plan in exchange for a lower premium. Also, it is unknown whether the current differences in premiums between restrictive and nonrestrictive health plans are substantial enough for people to choose a restrictive health plan consciously. We conducted a small scale choice experiment in order to answer these questions.

\section{MODEL AND HYPOTHESES}

In order to explain the choice of a restrictive health plan, we developed a model based on the rational choice theory (Lave and March, 1975) as was performed, for instance, by Kortenhoeven (1990). The focus here is on the core attributes of 
Bes, R.E., Curfs, E.C., Groenewegen, P.P., Jong, J.D. de. Health plan choice in the Netherlandss restrictive health plans preferred by young and healthy individuals. Health Economics, Policy and Law: 2017, 12(3), 345-362

freedom of choice and price. In addition, the travelling time will be included as this can be a consequence of selective contracting and patients generally dislike travelling (Varkevisser and Van der Geest, 2007). The goals of enrolees when choosing a health plan are: appropriate options for choosing care providers when they need care, low costs and a short travelling time to care providers. A short travelling time and appropriate options for choosing care providers are easily achieved when a nonrestrictive health plan is chosen; while costs are lowest when a restrictive health plan is chosen (Figure 1).

\subsection{Free choice}

Choosing a health plan with restrictions in provider choice could feel like taking a risk, as individuals do not know what care they will need in the future and which care providers they will want or need (Taylor, 1974). Individuals who are more risk averse in nature are, therefore, expected to avoid restrictive health plans. Generally, women are shown to be more risk averse than men (Jianakoplos and Bernasek, 1998) and, therefore, it is likely that men would choose a restrictive health plan more often than women.

Hypothesis 1:Men choose a restrictive health plan more often than women.

Elderly people are more at risk of needing care in the near future. Therefore, choosing a restrictive health plan is more risky for them. Thus, older people are expected to be less likely to choose a restrictive health plan.

Hypothesis 2:Younger people choose a restrictive health plan more often than older people.

People who are unhealthy visit care providers more regularly and are, thus, likely to have built a relationship with their care provider. Choosing a restrictive health plan will risk losing that relationship. Therefore, it is expected that people who are unhealthy are less likely to choose a restrictive health plan compared with healthy people.

Hypothesis 3:Healthy people choose a restrictive health plan more often than people who are less healthy.

\subsection{Travelling time}

People who are older or in poorer health may experience more trouble with their mobility. A longer travelling time is, therefore, expected to be a greater problem for them compared with people who are younger or healthier.

Hypothesis 4:People who are older or in poorer health will attach more value to a shorter travelling time and therefore be less likely to accept a longer travelling time in exchange for a lower premium. 
Bes, R.E., Curfs, E.C., Groenewegen, P.P., Jong, J.D. de. Health plan choice in the Netherlandsh restrictive health plans preferred by young and healthy individuals. Health Economics, Policy and Law: 2017, 12(3), 345-362

People who are in poorer health are unlikely to opt for a longer travelling time, as that implies a switch of care providers and it is more uncomfortable for them to travel. However, income may play a role in this as it is expected that people with income constraints are more price sensitive (Hoch et al., 1995; Marquis and Long, 1995) or simply may not be able to afford a health plan offering a free choice of provider. Therefore, we expect the relationship between health status and the acceptance of a longer travelling time will be different for people on a low income compared with those on a high income.

Hypothesis 5:People who are in poorer health and on a low income will accept, more often, a longer travelling time in exchange for a lower premium compared with people who are unhealthy but on a higher income.

\subsection{Price}

People on a low income are expected to be more sensitive to price, and may therefore value, more highly, the benefit of a lower premium compared with people on a higher income (Hoch et al. 1995; Marquis and Long, 1995; Scanlon et al., 1997). However, one consequence of opting for a restrictive health plan could be that enrolees have to travel further to attend the nearest care provider with whom their insurer has a contract. A longer travelling time is more costly, but, depending on the frequency of visits, it is likely that the yearly savings on the premium will override the extra costs of travelling further. It is also possible that enrolees are restricted by their low income. They cannot afford to buy a non-restrictive health plan and, therefore, have to choose a restrictive one. Thus, it is expected that individuals on a low income are more likely to give up their freedom of choice and/or short travelling time in exchange for a lower premium.

Hypothesis 6:People with a low income are more likely to exchange their freedom of choice and/or short travelling time for a lower premium.

Hypothesis 6 states that people on a low income would prefer to choose a restrictive health plan. However, the choice of a restrictive health plan poses more risks for individuals who are in poor health. The question is whether the savings on the premium are high enough to compensate for this risk. Choosing a restrictive health plan because of the low price may be less likely for people in poor health and on a low income compared with people in good health on a low income.

Hypothesis 7:People in good health on a low income would choose a restrictive health plan more often compared with people in poor health on a low income.

[FIGURE 1]

\section{METHODS}

\subsection{Participants and procedure}

The participants are members of the Insurance Panel. The Insurance Panel is an access panel of people aged 18 years and older, who all have health insurance. This 
Bes, R.E., Curfs, E.C., Groenewegen, P.P., Jong, J.D. de. Health plan choice in the Netherlandsh restrictive health plans preferred by young and healthy individuals. Health Economics, Policy and Law: 2017, 12(3), 345-362

panel was set up by the Netherlands Institute for Health Services Research together with a large Dutch health insurance cooperation (VGZ). Since earlier research showed that enrolees are not always aware of what health plan they have and what selective contracting is (Cunningham et al., 2001; Bes et al., 2014), we chose to conduct a survey in which simplified, hypothetical choice options are given, instead of looking at real life choice of health plan.

All panel members $(n=4370)$ were sent an online questionnaire by email. The questionnaire was completed by 3410 respondents $(78 \%)$.

\subsection{Questionnaire}

In the questionnaire, we use two different methods. First, respondents were presented with three hypothetical options for health plans (Table 1). The options were kept as realistic as possible with regard to the situation in the Netherlands. The first health plan (A) is the cheapest, but also the most restrictive and has a longer travelling time. The last health plan $(\mathrm{C})$ is the most expensive and has no restrictions in provider choice. Quality was kept constant between these choices, by stating that quality is high in every hypothetical health plan option, as research in the Netherlands has shown that people are hardly aware of any quality differences between hospitals or care providers (De Jong et al., 2006). Also, enrolees rarely indicate quality of care as a reason to switch health plans (Brabers et al., 2012). The benefits are the same between the three options as, in the Netherlands, benefits in terms of care provided in the basic health plan are determined by the government. The health plans differ in the number of care providers that are contracted and for what price. Respondents who did not choose the most restrictive health plan, were asked at what monthly premium they would be willing to choose this health plan, or, if they would never choose it and, if not, why not?

\section{[TABLE 1]}

Second, in order to look further into how enrolees weigh their freedom of choice and travelling time against price, respondents were given three sets of choices based on two health plans (Table 2). In set 1 , respondents had to make a choice between price and freedom of choice. In set 2, respondents had to choose between price and travelling time and in set 3 , respondents had to weigh price against both their travelling time and their freedom of choice. Again, the situations for the different choices were made to correspond, as realistically as possible, to the situation in the Netherlands. To control for left right bias, the choice sets were reversed for half the respondents.

\section{[TABLE 2]}

\subsection{Background characteristics}

Respondents fill in a questionnaire about their background characteristics when they register as a panel member. For every year following, they fill in a questionnaire about characteristics that can change over time. Therefore, background characteristics such as gender, age, self-reported health status (five-point scale from 
Bes, R.E., Curfs, E.C., Groenewegen, P.P., Jong, J.D. de. Health plan choice in the Netherlandsh restrictive health plans preferred by young and healthy individuals. Health Economics, Policy and Law: 2017, 12(3), 345-362

poor to excellent) and household income (ascending scale of 16 categories) are known. However, for this study, we wanted to include an indicator of health status i.e. more specifically aimed to measure use of care. Therefore, we added to the questionnaire the question, 'How often do you use your health insurance?'. The categories of responses were (1) never or barely, (2) sometimes, but I usually stay below my deductible, (3) regularly, I usually have to pay my deductible and (4) often. We use this variable in our analyses, except for the testing of Hypotheses 4 and 5. There, we believe self-reported health status is a more appropriate measure, as it is about how healthy someone feels to be able to travel.

\subsection{Analyses}

Data are analysed using STATA 13.0. First, the frequencies of the choices are presented. The frequencies are weighed to match the general Dutch adult population for age and gender. Second, logistic regression analyses are conducted for the three sets of choices shown in Table 2, in order to analyse differences in subgroups. Interaction effects that are not significant, are removed from the logistic regression models to facilitate interpretation of the other effects.

\section{RESULTS}

\subsection{Descriptive statistics}

Table 3 shows the descriptive statistics. Compared with the general Dutch population of 18 years and older, men are overrepresented in our sample $(57.2 \%$ vs $49.1 \%$ in general population) and the respondents are older on average (66.4 vs 48.7 in general population). Therefore, further results are weighted to match the general population for age and gender. We used six weighting factors ranging from 0.24 to 6.45.

\section{[TABLE 3]}

\subsection{The choice between three health plan options}

Table 4 shows that a small percentage of respondents $(6.6 \%)$ chose health plan A, the cheapest, most restrictive option. More respondents (37.9\%) chose health plan B, but the majority of respondents $(55.7 \%)$ chose health plan $\mathrm{C}$, which is the non-restrictive, most expensive, health plan. Furthermore, the table shows that women chose the non-restrictive health plan more often and that respondents who chose the nonrestrictive health plan are older compared with respondents who chose a restrictive health plan (A or B). Respondents who chose a restrictive health plan report a higher health status compared with respondents who chose the non-restrictive health plan, although the differences here seem very small. However, respondents who chose a restrictive health plan report significantly less use of health plan i.e. less use of care providers.

Of the respondents who chose health plan B, 74\% indicated that they would never choose health plan A. Of the respondents who chose health plan C, 87\% indicated they would never choose health plan A and $78 \%$ indicated they would never choose health plan B. Others indicated they would choose the other, more restrictive, health plans if they cost less. The reasons why respondents would never choose health plan A are that the number of contracted hospitals is too low, the travelling time is too 
Bes, R.E., Curfs, E.C., Groenewegen, P.P., Jong, J.D. de. Health plan choice in the Netherlandsh restrictive health plans preferred by young and healthy individuals. Health Economics, Policy and Law: 2017, 12(3), 345-362

long, and reimbursement for non-contracted care is too low. The reasons why respondents who chose health plan $\mathrm{C}$ would never choose health plan $\mathrm{B}$ are comparable with this.

\subsection{Choice sets}

Table 5 shows the results from the different sets of choices. Overall, most respondents chose the more expensive health plan options, i.e. the option with the most freedom of provider choice and/or the least amount of travelling time. However, this does not apply to all respondents. When the respondents weighed freedom of choice against price (choice set 1), 37\% chose the cheaper health plan with restrictions on choice, indicating that they are willing to give up some freedom of choice in exchange for a lower premium. When the cheaper option also includes a longer travelling time to the nearest care provider (choice set 3 ), then the number of people choosing the restrictive health plan decreases to $22 \%$. When respondents only weighed a longer travelling time against price (choice set 2), $45 \%$ chose the cheaper health plan with the longer travelling time. Overall, $15.8 \%$ chose the restrictive health plan in all the three situations and $37.9 \%$ chose the most expensive option in all three situations (not in table).

\section{[TABLE 5]}

\subsection{Differences in subgroups}

Table 6 shows three logistic regression analyses which we conducted for the three sets of choices. The results show that gender has no effect when respondents weigh freedom of choice against price (choice set 1). However, when they had to weigh price against freedom of choice and travelling time (choice set 3 ), the results show that men more often choose a restrictive health plan compared with women, partly confirming Hypothesis 1. Furthermore, the results show that age is an important predictor for the choice of a restrictive health plan (choice sets 1 and 3). Younger enrolees are more likely to choose a restrictive health plan, confirming Hypothesis 2. The use of health insurance has an effect when freedom of choice is involved in the choice set (choice sets 1 and 3), showing that enrolees who use their health insurance less, i.e. less often visit a care provider, choose a restrictive health plan more often, confirming Hypothesis 3.

\section{[TABLE 6]}

Older people and those in poorer health are less likely to choose a restrictive health plan, in general, but also when a longer travelling time is part of the restrictive health plan (choice set 1 and 3). When respondents weighed travelling time against price (choice set 2), then the interaction effect between self-reported health status and income was significant. To determine the nature of the effect, income was divided into two groups, low (income group 1 through $8 ; 45 \%$ of respondents) and high (income group 9 through $16 ; 55 \%$ of respondents). We estimated a model with two interaction terms, 'health status $\times$ low income' and 'health status $\times$ high income'. In Figure 2 the relationship between health status and choice was plotted for the two income groups. This shows that the relationship between health status and a 
Bes, R.E., Curfs, E.C., Groenewegen, P.P., Jong, J.D. de. Health plan choice in the Netherlandsh restrictive health plans preferred by young and healthy individuals. Health Economics, Policy and Law: 2017, 12(3), 345-362

willingness to accept a longer travelling time in exchange for a lower premium is stronger when income is high. This effect is also significant. When income is low, the relationship between health status and accepting a longer travelling time is not significant. Hypotheses 4 and 5 are therefore confirmed, as mobility influences the willingness to accept a longer travelling time in exchange for a lower premium. This effect does not exist for people on a low income. They are more likely to choose the cheaper health plan with a longer travelling time.

\section{[FIGURE 2]}

Lastly, Hypothesis 6 is confirmed, as income has a significant effect on all three choices. Furthermore, it was found that health status does not affect the relationship between income and the choice of a restrictive health plan, rejecting Hypothesis 7 (this effect was removed from the logistic regression models to facilitate the interpretation of the other effects).

\section{DISCUSSION}

Selective contracting and channelling enrolees to contracted care providers is very important for a health care system based on managed competition if it is to reach its goals of improving the quality of care and containing the cost. This is because it stimulates competition between care providers. In a restrictive health plan the choice of care provider is limited which may result in longer travelling distances for enrolees. However, restrictive health plans are also cheaper. The aim of this study was to find out who are willing to choose a restrictive health plan.

The results show that a significant number of people state that they are willing to accept restrictions to their freedom of provider choice in exchange for a lower premium (37\%). In the Netherlands, a restrictive health plan will not necessarily result in a longer travelling time, depending on how many care providers are contracted and where enrolees live. However, when the cheaper option also includes a longer travelling time to the nearest care provider, the number of people who choose the restrictive health plan decreases to $22 \%$. This shows that travelling time is important to many enrolees. The importance of travelling time is also found in other studies and is even used as a 'cost', as an alternative for price (Tai et al., 2004; Varkevisser et al., 2009). Older enrolees and those in poorer health find travelling time more important compared with younger enrolees and those in better health as they are less willing to accept a longer travelling time in exchange for a lower premium. However, the effect of health status is dependent on income. For people on a low income, the relationship between health and the willingness to accept a longer travelling time is not significant. People earning a higher income can afford the higher costs and, therefore, can determine their choice on their ability to travel. People on a low income do not have this luxury. The people who are willing to give up their freedom of provider choice for a lower premium are younger and healthier than the people who are not. This finding is consistent with literature from other countries (Hellinger, 1995; Hellinger and Wong, 2000; Lehman and Zweifel, 2004). 
Bes, R.E., Curfs, E.C., Groenewegen, P.P., Jong, J.D. de. Health plan choice in the Netherlandsh restrictive health plans preferred by young and healthy individuals. Health Economics, Policy and Law: 2017, 12(3), 345-362

It is important to note that the results are highly dependent on the values of the attributes in the options that were given. We do not know if the results would be the same if the restricted choice option would have been 30 instead of 50 hospitals, or when restricted choice option would have cost a monthly premium of 60 Euros instead of 70. It is expected that more people would have chosen the option of having a restricted choice if the price was lower and less if the option of having a restricted choice had included fewer hospitals. A more comprehensive choice experiment needs to be conducted in order to be certain about this. Recently, the results of such an experiment were published by Determan et al. (2016). However, as the aim of our study was to find out which people are more likely to choose a restrictive health plan, the method of our study was sufficient. This is also true because the values of the attributes were chosen to match the realistic situation in the Netherlands.

Furthermore, in the Netherlands, health insurers are obliged to reimburse part usually around $70 \%$ - of the costs of non-contracted hospitals. This means that the risk of choosing a restrictive health plan in the Netherlands is lower compared with countries where there is a lower reimbursement or no reimbursement at all for noncontracted care providers. In those countries the share of people who are willing to choose a restrictive health plan is likely to be lower compared with what was found in this study.

\subsection{Strengths and limitations}

A strength of this study is that in these different options, there was no status quo bias and respondents did not experience switching costs. In addition, the values chosen for the attributes in the different options were realistic with regard to the Dutch situation. Therefore, the results of this study indicate in how far people in the Netherlands are open to choosing a health plan with a restricted freedom of choice against price differences that currently exist in the market. However, a limitation is that as there are no switching costs or status quo bias, the results are likely to be an overestimation of the actual percentage of people who would choose a restrictive health plan. Furthermore, in practice, the options for making a choice between health plans are not as straightforward as shown in our experiment. When there is more information, or the information is presented in a complicated way, it is to be expected that people will rely more on price information instead of weighing up carefully all the different aspects of a health plan. Or they may even decide not to choose at all and to stay with their current health plan. Lastly, the respondents are all members of the Insurance Panel. Most of them have been with their current health insurer for a long time and can be considered loyal customers. We expect them to have more trust in their health insurer than other people. Therefore, it is expected that they would sooner choose a restrictive health plan compared with others (Bes et al., 2013). However, as the choices were hypothetical and the objective of this study was to look into differences in demographic characteristics, we believe that this has not influenced our results.

\subsection{Scientific implications}

A model was created to explain enrolees' choice of a restrictive health plan. Most of the connections hypothesised in the model were confirmed by the results. The effect of gender on the choice of a restrictive health plan is not completely clear as gender did not have an effect on the choice of price versus freedom of choice, but it did have 
Bes, R.E., Curfs, E.C., Groenewegen, P.P., Jong, J.D. de. Health plan choice in the Netherlandsh restrictive health plans preferred by young and healthy individuals. Health Economics, Policy and Law: 2017, 12(3), 345-362

an effect when the travelling time was included in this choice. It is likely that the experienced risk of choosing a restrictive health plan was greater when the travelling time increased while the price stayed the same, and thus did not compensate for the longer travelling time.

The interaction effect of health status and income on the choice of a restrictive health plan which we hypothesised was not confirmed. Income and health status both have a direct effect on the choice of health plan, but the effect of income is not different for respondents who enjoy good health compared with those who do not. Based on our available data, we cannot yet explain this, but it may be possible that the respondents in our panel are relatively healthy. Therefore, it would be very interesting to test the model in a natural experiment as well, for instance by monitoring which health plans are chosen by people who are forced to choose a new health plan, for instance when a collective health plan of an employer is cancelled.

The fact that enrolees who use care, less often choose restrictive health plans compared with healthier enrolees, could point at the absence of an important incentive for competition between care providers. If this incentive for competition is absent, the health care system based on managed competition theory is unlikely to reach its goals of improving quality of care while containing the costs by stimulating competition between care providers. This may also be the case in other countries where enrolees have a choice between restrictive and non-restrictive health plans.

\subsection{Policy implications}

The results of this paper show that there are enrolees willing to accept restrictions to their choice of provider in exchange for a lower premium. However, it also shows that these enrolees are healthier and less likely to need care. To reach the intended goals of the health care system, it is important that enrolees who use care also choose a restrictive health plan. The question then is: under what circumstances would more enrolees in poor health be willing to accept restrictions to their choice of provider? It is possible that the difference in price between restrictive and non-restrictive health plans is not large enough. Furthermore, the results may be different when the quality of care is taken into account. Enrolees in poor health are more likely to have experience with care providers and may find the quality of care more important. The idea of selective contracting is that health insurers select care providers based on price and quality. Assuming health insurers are indeed capable of selectively contracting higher quality care providers, it is possible that people in poor health or the elderly would choose a restrictive health plan. An important precondition for this is, however, that objective quality indicators are available and widely accepted. In the Netherlands, this is still a work in progress. Furthermore, as the elderly and people in poorer health are more concerned about increased travelling time, health insurers could, for instance, offer transportation to contracted care providers to overcome enrolees' unwillingness to travel further. Yet, selective contracting remains a negative incentive and therefore it may be questionable whether it will ever work as intended. Thus, one could also think about other solutions that might be regarded as more positive. Maybe health insurers should focus on positive incentives or simply only give advice to their enrolees about their choice of care provider. However, this is also difficult as enrolees are not used to asking their health insurer 
Bes, R.E., Curfs, E.C., Groenewegen, P.P., Jong, J.D. de. Health plan choice in the Netherlandsh restrictive health plans preferred by young and healthy individuals. Health Economics, Policy and Law: 2017, 12(3), 345-362

for advice and do not have much trust in their health insurer to act as a prudent purchaser of care on their behalf (Bes et al., 2012, 2013). The questions whether health insurers will be able to contract selectively based on quality and whether enrolees will ever trust health insurers to purchase good quality care on their behalf, are relevant for all countries implementing health care systems based on managed competition.

\section{Acknowledgements}

We would like to thank two anonymous reviewers for their constructive comments.

\section{Conflicts of Interest}

R.B., J.J., P.G. and J.J. declare that they have no competing interests. During the data collection E.C. was employed part-time (40\%) by VGZ.

\section{REFERENCES}

R. E. Bes , S. Wendel and J. D. de Jong (2012), 'Het vertrouwensprobleem van zorgverzekeraars [The trust issue of health insurers]', Economisch Statistische Berichten, 97(4647): 676-677.

R. E. Bes , S. Wendel , E. C. Curfs , P. P. Groenewegen and J. D. de Jong (2013), 'Acceptance of selective contracting: the role of trust in the health insurer', BMC Health Services Research, 13: 375. https://doi.org/doi:10.1186/1472-6963-13-375.

R. E. Bes , A. E. M. Brabers, M. Reitsma-van Rooijen and J. D. de Jong (2014), Selectief contracteren? Prima, maar beperk mijn keuzevrijheid niet! [Selective Contracting? Fine, but Do Not Restrict My Freedom of Choice!], Utrecht, the Netherlands: NIVEL.

R. E. Bes , E. C. Curfs , P. P. Groenewegen and J. D. de Jong (2015), 'Selective contracting and channelling patients to preferred providers: a scoping review', Health Policy (under review).

L. H. Boonen and F. T. Schut (2011), 'Preferred providers and the credible commitment problem in health insurance: first experiences with the implementation of managed competition in the Dutch health care system', Health Economics, Policy and Law, 6: 219235.

L. H. Boonen , F. T. Schut and X. Koolman (2008), 'Consumer channeling by health insurers: natural experiments with preferred providers in the Dutch pharmacy market', Health Economics, 17: 299-316.

L. H. Boonen , F. T. Schut , B. Donkers and X. Koolman (2009), 'Which preferred providers are really preferred? Effectiveness of insurers' channeling incentives on pharmacy choice', International Journal of Health Care Finance Economics, 9: 347-366.

A. E. M. Brabers , M. Reitsma-van Rooijen and J. D. de Jong (2012), 'The Dutch health insurance system: mostly competition on price rather than quality of care', Eurohealth Systems and Policies, 28(1): 30-32.

M. Chernew , D. P. Scanlon and R. Hayward (1998), 'Insurance type and choice of hospital for coronary artery bypass graft surgery', Health Services Research, 33(3): 447-466.

M. Y. L. Chu-Weininger and R. Balkrishnan (2006), 'Consumer satisfaction with primary care provider choice and associated trust', BMC Health Services Research, 6: 139.

P. J. Cunningham , C. Denk and M. Sinclair (2001), 'Do consumers know how their health plan works?', Health Affairs, 20(3): 159-166.

K. Davis , K. S. Collins , C. Schoen and C. Morris (1995), 'Choice matters: enrollees' views of their health plans', Health Affairs, 14(2): 99-112.

J. D. De Jong , P. P. Groenewegen and E. Van der Schee (2006), 'Consumenten en de stelselwijziging [Consumers and the health care reform]', Tijdschrift voor Gezondheidswetenschappen, 84(5): 288-2091. 
Bes, R.E., Curfs, E.C., Groenewegen, P.P., Jong, J.D. de. Health plan choice in the Netherlands: restrictive health plans preferred by young and healthy individuals. Health Economics, Policy and Law: 2017, 12(3), 345-362

D. Determan , M. S. Lambooij, E. W. de Bekker-Grob, A. P. Hayen, M. Varkevisser, F. T. Schut and G. A. de Wit (2016), 'What health plans do people prefer? The trade off between premium and provider choice', Social Science \& Medicine, 165: 10-18.

Dutch Health Care Authority (2007), Richting geven aan keuzes. Kunnen verzekeraars consumenten stimuleren naar gecontracteerde voorkeursaanbieders te gaan? [Directions to Choices. Can Health Insurers Stimulate Consumers to Visit Contracted Preferred Providers?], Utrecht, the Netherlands: Dutch Health Care Authority.

Dutch Health Care Authority (2015), Zeventien zorgpolissen nader bekeken. In relatie tot de zorgplicht [A Closer Look at Seventeen Health Plans. In Relation to the Duty to Care], Utrecht, the Netherlands: Dutch Health Care Authority.

A. C. Enthoven (1993), 'The history and principles of managed competition', Health Affairs, 12(1): 24-48.

A. C. Enthoven (2008), 'A living model of managed competition: a conversation with Dutch health minister Ab Klink', Health Affairs, 27(3): 196-203.

F. J. Hellinger (1995), 'Selection bias in HMOs and PPOs: a review of the evidence', Inquiry, 32(4): 135-142.

F. J. Hellinger and H. S. Wong (2000), 'Selection bias in HMOs: a review of the evidence', Medical Care Research and Review, 57(4): 405-439.

S. J. Hoch , B. D. Kim , A. L. Montgomery and P. E. Rossi (1995), 'Determinants of storelevel price elasticity', Journal of Marketing Research, 32: 17-29.

N. A. Jianakoplos and A. Bernasek (1998), 'Are women more risk averse?', Economic Enquiry, 36(4): 620-630.

P. Kemper , H. T. Tu , J. D. Reschovsky and E. Schaefer (2002), 'Insurance product design and its effects: trade-offs along the managed care continuum', Inquiry, 39: 101-117.

D. Kortenhoeven (1990), Vrouwelijke artsen en vestiging als huisarts [Female Physicians Establishing a General Practice], Utrecht, the Netherlands: Bohn, Scheltema \& Holkema.

T. Laske-Aldershof , E. Schut, K. Beck, S. Gress , A. Shmueli and C. Van de Voorde (2004), 'Consumer mobility in social health insurance markets: a five country comparison', Applied Health Economics and Health Policy, 3: 229-241.

C. A. Lave and J. G. March (1975), An Introduction to Models in the Social Sciences, New York: HarperCollins Publishers.

H. Lehman and P. Zweifel (2004), 'Innovation and risk selection in deregulated social health insurance', Journal of Health Economics, 23: 997-1012.

S. M. Marquis and S. H. Long (1995), 'Worker demand for health insurance in the nongroup market', Journal of Health Economics, 14: 47-63.

M. M. Mello , S. C. Stearns , E. C. Norton and T. C. Ricketts (2003), 'Understanding biased selection in medicare HMOs', Health Services Research, 38(3): 961-992.

M. Rijken , I. de Putter , M. Reitsma-van Rooijen , P. Spreeuwenberg , J. D. de Jong and P. P. Groenewegen (2015), 'Illness-related expenditures of people with chronic illness and of the general Dutch population: mind the gap!', Health Policy (under review).

D. P. Scanlon , M. Chernew and J. R. Lave (1997), 'Consumer health plan choice: current knowledge and future directions', Annual Review of Public Health, 18: 507-528.

J. Schmittdiel , J. V. Selby , K. Grumbach and C. P. Quesenberry (1997), 'Choice of a personal physician and patient satisfaction in a health maintenance organization', Journal of the American Medical Association, 278(19): 1596-1599.

A. T. Sorensen (2003), 'Insurer-hospital bargaining: negotiated discounts in postderegulation Conneticut', Journal of Industrial Economics, 51(4): 469-490.

W. T. C. Tai , F. W. Porell and E. K. Adams (2004), 'Hospital choice of rural medicare beneficiaries: patient, hospital attributes and patient-physician relationship', Health Services Research, 39(6, Pt 1): 1903-1922.

M. Tai-Seale and B. Pescosolido (2003), 'The public's opinions of physicians: Do perceived choice and exercised choice matter?', The American Journal of Managed Care, 9(9): 631638.

J. W. Taylor (1974), 'The role of risk in consumer behavior', Journal of Marketing, 38: 5460.

H. T. Tu (2005), 'More Americans willing to limit physician-hospital choice for lower medical costs', Center for Studying Health System Change, 94: 1-5. 
Bes, R.E., Curfs, E.C., Groenewegen, P.P., Jong, J.D. de. Health plan choice in the Netherlands: restrictive health plans preferred by young and healthy individuals. Health Economics, Policy and Law: 2017, 12(3), 345-362

W. P. Van de Ven, K. Beck, F. Buchner, E. Schokkaert, F. T. Schut, A. Shmueli and J. Wasem (2013), 'Preconditions for efficiency and affordability in competitive healthcare markets: are they fulfilled in Belgium, Germany, Israel, the Netherlands and Switzerland?', Health Policy, 109: 226-245.

M. Varkevisser and S. A. Van der Geest (2007), 'Why do patients bypass the nearest hospital? An empirical analysis for orthopaedics care and neurosurgery in the Netherlands', European Journal of Health Economics, 8(3): 287-295.

M. Varkevisser, S. A. Van der Geest and F. T. Schut (2009), 'Assessing hospital competition when prices don't matter to patients: the use of time-elasticities', International Journal of Health Care Finance Economy, 10(1): 43-60.

V. Y. Wu (2009), 'Managed care's price bargaining with hospitals', Journal of Health Economics, 28: 350-360.

\section{FigURES AND TABLES}

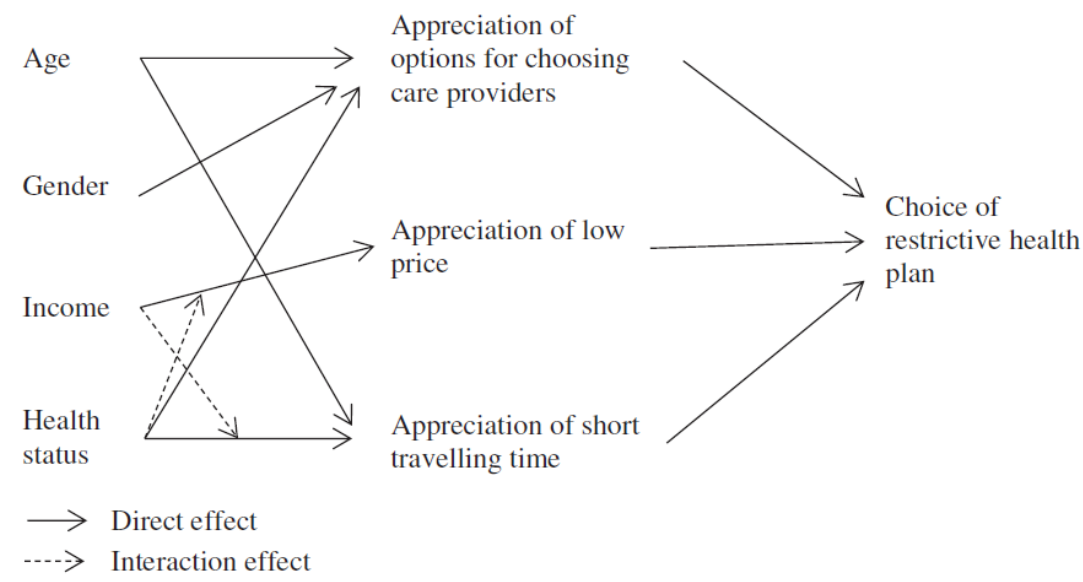

Figure 1. Model to explain the choice of a restrictive health plan.

Table 1. Three options for choosing a health plan shown to respondents

\begin{tabular}{lccc}
\hline \hline & Health plan A & Health plan B & Health plan C \\
\hline Monthly premium $(€)$ & 75 & 85 & 95 \\
Number of contracted hospitals in the Netherlands & 40 & 80 & 100 (all) \\
Travelling time to the nearest hospital (minutes) & 40 & 20 & 20 \\
Reimbursement for non-contracted hospitals (\%) & 50 & 70 & n.a. ${ }^{\text {a }}$ \\
Quality of contracted care providers & High & High & High \\
\hline \hline
\end{tabular}

Note: Contracting only applies to non-emergency care. Emergency care is always fully reimbursed by all health plans at all hospitals.

${ }^{a}$ Not applicable. 
Bes, R.E., Curfs, E.C., Groenewegen, P.P., Jong, J.D. de. Health plan choice in the Netherlands: restrictive health plans preferred by young and healthy individuals. Health Economics, Policy and Law: 2017, 12(3), 345-362

Table 2. Overview of the three sets of choices presented to respondents

\begin{tabular}{|c|c|c|c|c|c|c|}
\hline \multirow{2}{*}{$\begin{array}{l}\text { Choice set } \rightarrow \\
\text { Attributes } \downarrow \\
\end{array}$} & \multicolumn{2}{|c|}{$\begin{array}{l}1 \text { (price vs } \\
\text { freedom of } \\
\text { choice) }\end{array}$} & \multicolumn{2}{|c|}{$\begin{array}{l}2 \text { (price vs } \\
\text { travelling time) }\end{array}$} & \multicolumn{2}{|c|}{$\begin{array}{c}3 \text { (price vs freedom } \\
\text { of choice and } \\
\text { travelling time) }\end{array}$} \\
\hline & A & B & $\mathrm{A}$ & B & A & B \\
\hline Monthly premium $(€)$ & 90 & 70 & 90 & 70 & 90 & 70 \\
\hline $\begin{array}{l}\text { Number of hospitals contracted in the Netherlands } \\
\text { (100 is the total) }\end{array}$ & 100 & 50 & 50 & 50 & 100 & 50 \\
\hline Travelling time to the nearest hospital (minutes) & 20 & 20 & 20 & 40 & 20 & 40 \\
\hline Reimbursement for non-contracted hospitals (\%) & n.a. ${ }^{a}$ & 70 & 70 & 70 & n.a. & 70 \\
\hline Quality of contracted care providers & High & High & High & High & High & High \\
\hline
\end{tabular}

Note: Contracting only applies to non-emergency care. Emergency care is always fully reimbursed by all health plans at all hospitals. Attributes in bold differ from each other in the set.

${ }^{\mathrm{a}}$ Not applicable.

Table 3. Descriptive statistics

\begin{tabular}{|c|c|c|}
\hline Variables & Per cent/mean & $n$ \\
\hline Men & $57.2 \%$ & 3410 \\
\hline Age $(\mathrm{SD})$ & $66.4(12.5)$ & 3410 \\
\hline Self-reported health status ${ }^{a}$ & 3.0 & 3359 \\
\hline
\end{tabular}

${ }^{\mathrm{a}}$ Measured on a five-point scale from poor (1) to excellent (5).

Table 4. Results for the first choice situation, three options for a choice of health plan ${ }^{\mathrm{a}, \mathrm{b}}(n=367)$

\begin{tabular}{lccc}
\hline \hline & Health plan A & Health plan B & Health plan C \\
\hline Total (\%) & 6.6 & 37.9 & 55.6 \\
Men (\%) & 51.6 & 51.0 & 47.7 \\
Age (mean) & 48.3 & 48.6 & 54.7 \\
Self-reported health status c (mean) & 3.1 & 3.3 & 3.1 \\
Use health plan regularly - a lot (\%) & 38.9 & 34.0 & 49.7 \\
\hline \hline
\end{tabular}

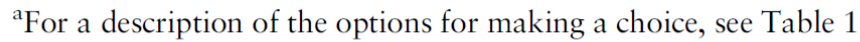

${ }^{b}$ Results are weighted to match the general Dutch population for age and gender.

${ }^{\mathrm{c}}$ Measured on a five-point scale from poor (1) to excellent (5). 
Bes, R.E., Curfs, E.C., Groenewegen, P.P., Jong, J.D. de. Health plan choice in the Netherlands: restrictive health plans preferred by young and healthy individuals. Health Economics, Policy and Law: 2017, 12(3), 345-362

Table 5. Results for the different choice sets ${ }^{\mathrm{a}, \mathrm{b}}$

\begin{tabular}{|c|c|c|c|c|c|}
\hline \multicolumn{2}{|c|}{$\begin{array}{l}\text { Choice set } 1 \text { (price vs } \\
\text { freedom of choice) }\end{array}$} & \multicolumn{2}{|c|}{$\begin{array}{l}\text { Choice set } 2 \text { (price vs } \\
\text { travelling time) }\end{array}$} & \multicolumn{2}{|c|}{$\begin{array}{c}\text { Choice set } 3 \text { (price vs freedom of choice } \\
\text { and travelling time) }\end{array}$} \\
\hline A & B & A & B & A & B \\
\hline 62.6 & 37.4 & 55.0 & 45.0 & 77.9 & 22.1 \\
\hline
\end{tabular}

${ }^{a}$ For a description of the different choice sets, see Table 2 .

${ }^{b}$ Percentages were weighted to match the general population for age and gender.

Table 6. Logistic regression analyses per choice set

\begin{tabular}{lccc}
\hline \hline $\begin{array}{l}\text { Dependent var } \rightarrow \\
\text { Independent vars } \downarrow\end{array}$ & $\begin{array}{c}\text { Choice set } 1^{\mathrm{a}} \\
\text { Coef. }\end{array}$ & $\begin{array}{c}\text { Choice set } 2^{\mathrm{a}} \\
\text { Coef. }\end{array}$ & $\begin{array}{c}\text { Choice set } 3^{\mathrm{a}} \\
\text { Coef. }\end{array}$ \\
\hline Gender $(0=\mathrm{f}, 1=\mathrm{m})$ & 0.086 & 0.117 & $0.218^{\mathrm{a}}$ \\
Age & $-0.022^{* *}$ & $-0.014^{* *}$ & $-0.013^{* *}$ \\
Income & $-0.025^{*}$ & $-0.079^{*}$ & $-0.030^{*}$ \\
Health status & - & -0.022 & - \\
Use of health plan $^{\mathrm{c}}$ & $-0.297^{* *}$ & - & $-0.302^{*}$ \\
Health status $\times$ income & - & $-0.023^{*}$ & - \\
\hline \hline
\end{tabular}

Notes: $-=$ not included in the model.

${ }^{\mathrm{a}} 0=$ expensive option and $1=$ cheap option; $* \mathrm{p} \leqslant 0.05 ; * \mathrm{p} \leqslant 0.001$.

${ }^{\mathrm{b}}$ Measured on a five-point scale from poor (1) to excellent (5).

${ }^{\mathrm{c}}$ Measured on a four-point scale and divided into two groups: 0 (never or barely - sometimes) and 1 (regularly - often)

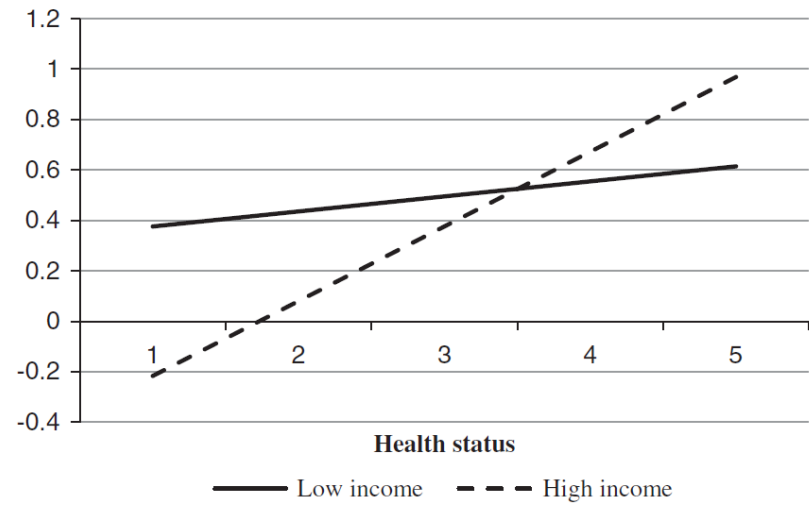

Figure 2. The relationship between health status and a willingness to accept a longer travelling time (on a logistic scale) in exchange for a lower premium. Plotted for two income groups. Note: The following equation was used to calculate the plots:

$\mathrm{Y}=$ Constant $+\mathrm{X}_{\mathrm{low}}$ (income; $1=$ low, $0=$ high $)+\mathrm{Z}$ (health) $\mathrm{X}_{\mathrm{low}}+\mathrm{ZX}_{\mathrm{high}}$ (income; $1=$ high, $0=$ low). 